Las manifestaciones de la actual pandemia se expresan fundamentalmente en el ámbito urbano, el principal espacio de las concentraciones de población y la dinámica productiva y social. En el medio rural también se expresan los efectos directos o indirectos de la irrupción de la emergencia sanitaria. Principalmente, se han identificado efectos en la producción agrícola, en las economías locales y en el sistema agroalimentario, en donde se plantean opciones alternas a la actual modalidad de la producción y el abasto de alimentos en los centros urbanos.

Palabras clave: ruralidad, agricultura periurbana, agroecología, sistema agroalimentario, circuitos cortos

\title{
Algunos impactos de la emergencia sanitaria en los espacios rurales
}

Héctor Ávila Sánchez ahector@unam.mx

Las manifestaciones del covid-19, se expresan fundamentalmente en el medio urbano, sea en los sistemas metropolitanos o bien en ciudades medias, donde existen las concentraciones poblacionales y la gran mayoría de las actividades económicas y sociales. Sin embargo, en el medio rural también tienen lugar impactos precisos, principalmente en la producción agropecuaria, en la dinámica de los sistemas agroalimentarios y en las economías locales, sostenidas por las remesas de los migrantes. Igualmente, la pandemia impacta en los patrones migratorios de los jornaleros agrícolas estacionales, en el caso de México, hacia los campos agrícolas del norte y noroeste.

En términos macroeconómicos, el efecto es de alta consideración, pues se calcula que el producto interno bruto agropecuario caerá en promedio entre 5 y $6 \%$, en el conjunto de países latinoamericanos (FAO, 2020). En México replicará de forma diferenciada

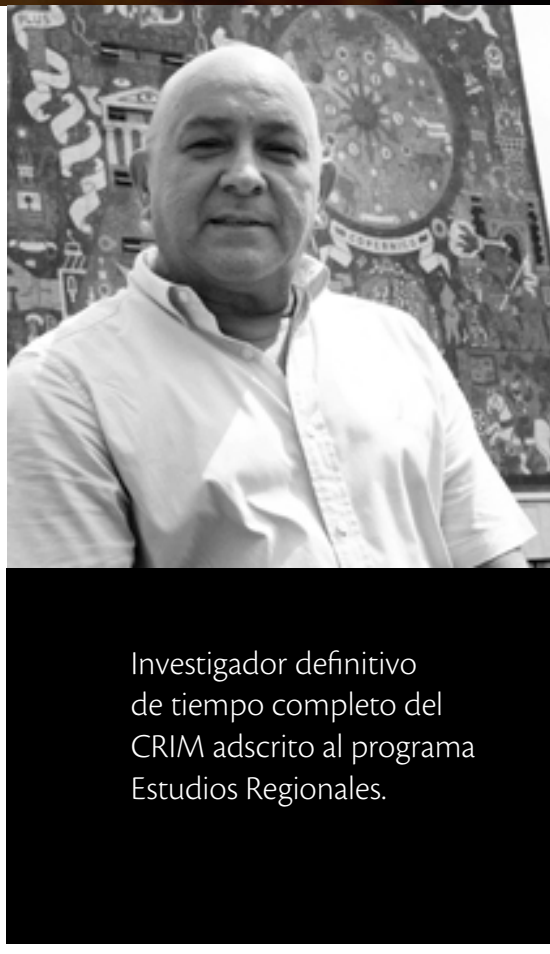




\section{ca}

Una alta cantidad de jornaleros

continúan trabajando y,

a pesar de supuestamente adoptar

las medidas sanitarias requeridas,

se encuentran en un alto riesgo de contagio." en sus distintas regiones. En contraste con la dinámica socio-productiva de las zonas urbanas, en el campo, las actividades muestran dos facetas. Donde la producción de alimentos no se ha detenido; en las zonas de agricultura familiar y/o campesina, los productores continúan con sus actividades y acuden cotidianamente a los mercados locales, en donde venden sus cultivos; en el oriente de Morelos (Cuautla, Axochiapan, Ayala), continúan con la cosecha de elote, para su venta en las centrales de abasto - sobre todo locales-. La producción de flores y plantas de ornato a cielo abierto y en viveros, realizada por pequeños productores en la Zona Metropolitana de Cuernavaca (Jiutepec, Temixco, Emiliano Zapata y Tetela del Monte), continúa con su actividad, con una notoria baja en la demanda.

Una prueba de que la actividad continúa en el medio rural mexicano, lo representa el hecho de que el abasto de alimentos se ha mantenido de manera casi normal, pues durante el mes de abril de 2020, llegaban a la Central de Abastos de la Ciudad de México, los volúmenes regulares para esa época del año (aproximadamente 45 mil toneladas de frutas, verduras, carnes y abarrotes), para surtir a los mercados de la zona metropolitana de la Ciudad de México (Rimisp, 2020). Cabe señalar que este lugar, debido a su intenso dinamismo, ha sido identificado como uno de los mayores focos de contagio a nivel nacional.

En otras zonas del país, de agricultura intensiva vinculada a los mercados de exportación, continúan laborando una gran cantidad de jornaleros y a pesar de supuestamente adoptar las medidas sanitarias requeridas, se encuentran en un alto riesgo de contagio. Por ello el temor de regresar a sus comunidades, desde los productivos campos del Valle de San Quintín o Mexicali en Baja California, o de los valles agrícolas en Sonora y Sinaloa. Algunos flujos menores de jornaleros agrícolas de Morelos (de la región oriente, principalmente), se dirigen cada año, desde fines de la década de los años 90, a la cosecha de la uva en Sonora (Pesquería) y al ciclo productivo de frutas y hortalizas en el Valle de Culiacán (Saldaña, 2014). Este último punto también ha sido identificado como un foco de alto contagio del virus.

Por otra parte, en muchas regiones del país el impacto se expresa en la baja demanda de productos agrícolas. En Villa Guerrero, Coatepec y Tenancingo, poblaciones del suroeste del Estado de México dedicadas casi por entero a la producción de flores, la pandemia ocasionó un descenso de $80 \%$ en la venta, afectando la economía de 25000 productores (Jiménez, 2020). La situación se agrava con el cierre temporal del mercado de flores de Jamaica, el más grande de la Ciudad de México, donde los productores mexiquenses colocaban parte de su producción.

Las remesas que envían los migrantes desde Estados Unidos, constituyen una fuente fundamental en las economías rurales en México. Dan vida a un creciente sector de servicios y financian la creación de industrias locales pequeñas. Morelos no es la excepción; la entidad mantiene una creciente participación de trabajadores migrantes en Estados Unidos, que reportan importantes ingresos a comunidades rurales en el Estado. En el año 2019 (enero-diciembre), las remesas recibidas en Morelos alcanzaron 702.6 millones de dólares, $1.9 \%$ del total nacional y coupando el lugar 21 entre las entidades receptoras (Banco de México, 2019). Si bien se ha registrado una disminución en cuanto a la llegada de remesas, aun así, son de gran importancia en la economía estatal. El total de las remesas recibidas durante 2019, representa casi la mitad del presupuesto estatal para el estado 
de Morelos en 2020. Los municipios con mayor recepción son Cuautla, 34 millones de dólares; Cuernavaca, con 32 y Axochiapan con 16 millones (trimestre junio-septiembre, 2019). La disminución progresiva de las remesas se agravará con la crisis del covid-19 y resentirán esta baja, aquellos municipios que desarrollan actividades económicas diversas (comercio y servicios) a partir de estos ingresos (Resienten en Axochiapan la reducción de remesas, 2020)

Otra cuestión vinculada con los posibles efectos de la pandemia, es el nivel o grado de aislamiento que presentan las localidades

$\boldsymbol{c}$

En la actual circunstancia del coviD-19,

se requiere asegurar una efectiva y rápida

movilidad de la población de municipios rurales

hacia los centros urbanos." rurales, con respecto a las ciudades medias y las zonas metropolitanas, donde se concentra la infraestructura sanitaria para la atención a la población. Este contexto incide en la vulnerabilidad de las comunidades indígenas arraigadas a su entorno, en zonas montañosas con condiciones de alta marginalidad (por ejemplo, en la Tarahumara, en la Montaña de Guerrero, los Altos de Chiapas y la Sierra de Zongolica, entre otros). En el caso del estado de Morelos, la situación no plantea mayores problemas, en primera instancia debido a que más de $70 \%$ de la población habita en zonas urbanas, además que se concentra en zonas de planicie y valles fluviales. Las zonas montañosas en la entidad, en el norte, norponiente y sur; no constituyen un gran obstáculo para el traslado rápido de la población que así lo requiera. Sin embargo, en la actual circunstancia del covid-19, se requiere asegurar una efectiva y rápida movilidad de la población de municipios rurales hacia los centros urbanos donde se encuentra la infraestructura sanitaria. En este sentido, la red carretera estatal parece cumplir con las expectativas de conexión a nivel local y regional, dada su cercanía con otras metrópolis regionales (Ciudad de México, Toluca y Puebla).

En los espacios de producción agrícola, uno de los impactos de la pandemia tiene que ver con la caída de la producción, forzada por la limitación de la movilidad debido al confinamiento y falta de liquidez de los productores, lo que interrumpe las cadenas productivas alimentarias. Si bien la producción agropecuaria de alimentos para el abasto de los centros urbanos se realiza en gran parte bajo el modelo convencional productivista - de grandes volúmenes y provenientes desde largas distancias-, la coyuntura actual de la crisis sanitaria resalta la importancia de modelos y formas alternativas, que tienen ya una cierta difusión. Se ha configurado una agricultura de proximidad, la que se realiza en espacios rurales cercanos a las ciudades (en las zonas periurbanas), lo que posibilita el traslado cotidiano desde las zonas de producción de los cultivos, hacia los centros de distribución y consumo. En el centro del país, algunos de los volúmenes de hortalizas y productos perecederos que surten los requerimientos de abasto de la megalópolis central del país, provienen de zonas agrícolas periurbanas, localizadas en algunos municipios de los estados de la Corona Regional de la Ciudad de México (Estado de México, Puebla, Tlaxcala, Hidalgo, Morelos y Ciudad de México).

En los últimos tiempos se ha discutido acerca de los altos costos ambientales y sociales del modelo agroalimentario prevaleciente. Se ha debatido la importancia de construir "iniciativas de participación social encaminadas a favorecer la producción agroecológica y de abasto para segmentos de poblaciones metropolitanas, desde mercados y tianguis que impulsan circuitos cortos y economías solidarias (...) procesos de fortalecimiento, lazos de solidaridad y confianza entre productores y consumidores, con participación importante de zonas periurbanas de producción agropecuaria de proximidad" (Conacyt, 2020). 
ca

La coyuntura actual de la crisis sanitaria

resalta la importancia

de modelos y formas alternativas."
En la presente circunstancia, se ha generalizado la provisión de alimentos a domicilio, como una forma de evitar la propagación del virus; asimismo, es una de las formas en que los productores agrícolas y los ofertantes de restauración enfrentan la crisis económica.

Si bien, su aporte es aún de escasa significancia económica, los espacios agrícolas periurbanos de proximidad, tienen ya presencia en el abasto alimentario en los centros metropolitanos. En estos ámbitos existen productores familiares, así como también, pequeños productores privados, que participan el proceso, conformando circuitos cortos de comercialización y consumo, donde la producción llega directa o casi directamente al consumidor, a través de surtir cestas y/o cajas de alimentos diversos (regularmente orgánicos y sanos). Se trata de modalidades similares a las existentes en otros países, que se fundamentan en sistemas solidarios y de confianza entre productores y consumidores, como los Community Support Agriculture (csa) y las Amap (Asociaciones para el Mantenimiento de la Agricultura Campesina, en Francia), de gran vigencia en Europa y América del Norte.

Quizá la coyuntura de la pandemia podría constituir la oportunidad de fortalecer esta modalidad de la agricultura periurbana. Es una opción de difícil concreción, pues en países latinoamericanos no existe un nicho suficiente de consumidores que sustente el proceso y su consideración dentro de las políticas públicas de desarrollo rural es incipiente y cuenta con apoyos gubernamentales muy limitados. Sin embargo, el fortalecimiento y el impulso aún mayor a estas modalidades, incorporaría dentro del sistema agroalimentario a un abanico más amplio de productores pequeños, que difícilmente se sostienen como agricultores, sean ejidatarios o privados. Se pretendería además que, a través de fortalecer los circuitos cortos de distribución - que eliminaría a la mayor cantidad posible de intermediarios en la cadena de valor-, se optimizaran los beneficios, tanto para productores como consumidores.

\section{Notas}

1 Jornaleros agrícolas del pueblo Me'phaa de la Montaña de Guerrero, trabajan actualmente, en plena pandemia, en labores de cosecha en los campos agrícolas de Villa Unión, en Mazatlán, Sinaloa (Tlachinollan, 2020). Hasta diciembre de 2019, se habían registrado 98 empresas agrícolas donde trabajaban jornaleros de La Montaña, principalmente en Sinaloa, pero también en Sonora, Baja California, Nayarit, Jalisco, Guanajuato y San Luis Potosí (Ibid.).

2 El mejor ejemplo lo representa el abasto de nopal verdura producido en la región agrícola nopalera de Milpa Alta-Tlalnepantla, Morelos, la mayor productora nacional. En menor medida también se incorporan a las grandes centrales de abasto y mercados locales, volúmenes importantes de ejotes (oriente de Morelos) y jitomate (Altos de Morelos).

3 Como las asociaciones \#canastaxméxico, una iniciativa de economía sustentable y social que involucra la venta en línea de productos orgánicos y convencionales de pequeños productores (https://www.canastaxmexico.com/). En Xochimilco se ha constituído De la chinampa, sociedad compuesta por pequeños productores, que comercializa sus produc- 
tos naturales y artesanales — como alimentos derivados de la leche, hortalizas y frutas, y huevo de libre pastoreo- en reserva ecológica de Cuemanco (https://www.delachinampa.mx/). Otras organizaciones de productores como Yolcan (https://www.yolcan.com/), realizan prácticas agrícolas sustentables y orgánicas, con la intención de salvaguardar las chinampas como patrimonio territorial y paisajístico de Xochimilco, más allá de la rentabilidad económica. Producen mezclas de ensaladas y otros cultivos (espinacas, cebollines, hierbas finas, brócolis y ejotes) para la cocina gourmet. Asimismo, venden alimentos diversos a la empresa Green Corner, además de realizar entregas semanales de cestas o cajas de hortalizas a consumidores directos en el sur de la Ciudad de México (Ávila, 2018).

\section{Referencias}

Ávila, H. (2018) "Prácticas agrícolas y gestión territorial en espacios rururbanos de la zona metropolitana de la Ciudad de México: el caso de Xochimilco”, en Sanz, J. y Delgadillo, J (coords.) Sistemas agroalimentarios de proximidad. Contextos rurubanos en México y España. Instituto de Investigaciones Económicas-unam; Consejo Superior de Investigaciones Científicas-Instituto de Economía, Geografía y Demografía.

Banco de México (2019). Sistema de Información Económica (2019). https://www.banxico. org.mx/SieInternet/

Conacyt (2020). Programa de soberanía alimentaria de pronta respuesta en agriculturas de pequeña y mediana escala. Dirección Regional Centro. Documento interno.

FAO (2020). El COVID-19 y su impacto sobre la agricultura y la alimentación en América Latina y el Caribe. https://www.youtube.com/watch?v=QOwkCB5k2ik\&t=11s

Jiménez, R. (4 de mayo de 2020). Pandemia pega a floricultores en el Edomex. El Universal.https://www.eluniversal.com.mx/metropoli/edomex/pandemia-pegafloricultores-en-el-edomex

Resienten en Axochiapan la reducción de remesas. (16 de abril de 2020). La Jornada de Morelos. https://www.lajornadamorelos.com.mx/municipios/2020/04/16/18685/ resienten-en-axochiapan-la-reducci\%C3\%B3n-remesas

Rimisp. (29 de abril de 2020). El COVID-19 y su impacto en el abastecimiento de alimentos en Colombia, México y Chile. https://webnueva.rimisp.org/noticia/el-covid-19-y-suimpacto-en-el-abastecimiento-de-alimentos-en-colombia-mexico-y-chile/

Saldaña, A. (2014). Intermediarios laborales en Morelos: abasto de jornaleros agrícolas en el centro y noroeste de México. Estudios sociales (Hermosillo, Son.), 22 (43), 137-158. http://www.scielo.org.mx/scielo.php?script=sci_arttext\&pid=S018845572014000100006\&lng=es\&tlng=es

Tlachinollan. (17 de abril de 2020). NOTA INFORMATIVA | Familias Me'phaa de la Montaña de Guerrero trabajan en los campos agricolas en plena pandemia. http:// www.tlachinollan.org/nota-informativa-familias-mephaa-de-la-montana-deguerrero-trabajan-en-los-campos-agricolas-en-plena-pandemia/

Para citar esta nota: Ávila, H. (1 de junio de 2020). Algunos impactos de la emergencia sanitaria en espacios rurales. Notas de coyuntura del CRIM No. 24, México, CRIm-unAm, 5 pp. 